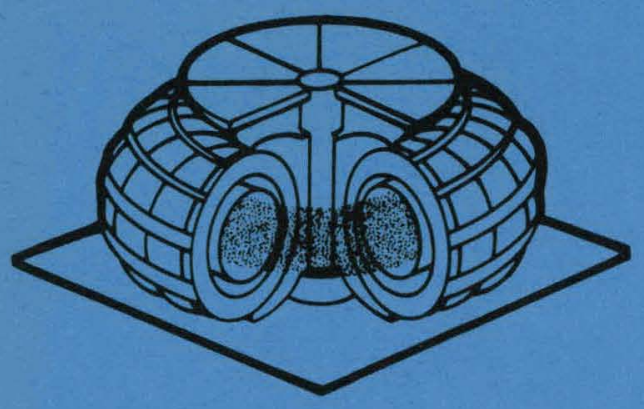

$$
\begin{aligned}
& \text { WFPS-TME-0O7 } \\
& \text { OCTOBER } 1975
\end{aligned}
$$

\title{
MASILA
}

Westinghouse Electric Corporation
Fusion Power Systems Department

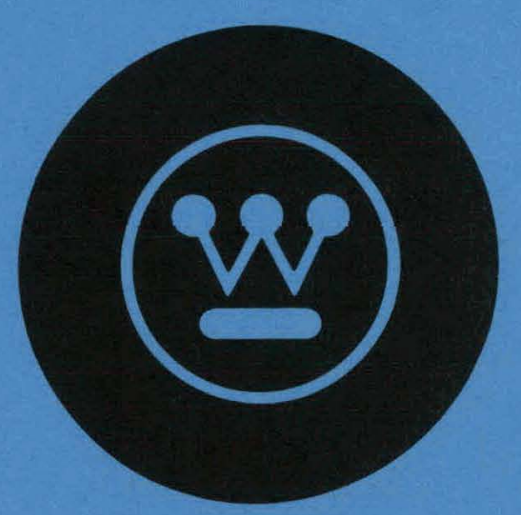

\section{TFTR CENTRAL INSTRUMENTATION AND CONTROL PHILOSOPHY}




\section{DISCLAIMER}

This report was prepared as an account of work sponsored by an agency of the United States Government. Neither the United States Government nor any agency Thereof, nor any of their employees, makes any warranty, express or implied, or assumes any legal liability or responsibility for the accuracy, completeness, or usefulness of any information, apparatus, product, or process disclosed, or represents that its use would not infringe privately owned rights. Reference herein to any specific commercial product, process, or service by trade name, trademark, manufacturer, or otherwise does not necessarily constitute or imply its endorsement, recommendation, or favoring by the United States Government or any agency thereof. The views and opinions of authors expressed herein do not necessarily state or reflect those of the United States Government or any agency thereof. 


\section{DISCLAIMER}

Portions of this document may be illegible in electronic image products. Images are produced from the best available original document. 
WFPS-TME-007

OCTOBER 1975

\section{TFTR CENTRAL INSTRUMENTATION AND CONTROL PHILOSOPHY}

Aepared by:

J. M. Walsh

Approved by:

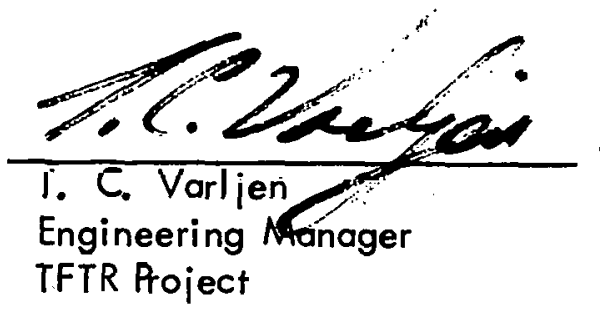

Approved by:

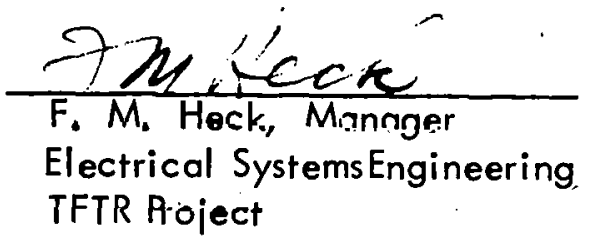

Westinghouse Electric Corporation

Fusion Power Systems Department

Post Office Box 10864

Ritsburgh, Pennsylvania 15236 


\begin{abstract}
This report documents a conceptual study performed to develop a central instrumentation and control philosophy for the TFTR facility. This study addresses the following questions:

- What are the various control and monitoring functions involved?

- How many and what different kinds of qualified operating personnel are to be provided?

- How are the various control and monitoring functions, and as a result the control personnel, to be assigned to the central control station?

- How is the crucially important experimental data handling, processing, and analysis function to be interfaced with the facility control functions?

- What modes require back shift operating personnel?
\end{abstract}

In this report the present central control operating philosophy is stated with discussion of the principles underlying its choice. The report is organized so that the statement of control philosophy is given in one paragraph, and the basis for this choice is given in the following paragraph. Each statement of the control philosophy addresses one of the specific questions above.

The cúrrent conceptual design of the TFTR systems and the present plans for operating the pulsed experiments were reviewed in order to determine the control functions and control monitoring that would be needed to take facility equipment through the anticipated operations. Based on the facility design definition to date, it appears that a control group consisting of a qualified test director, a qualified shift supervisor, a qualified experimental device operator, four qualified control room operators and four to six experimenter/ physicists would provide the minimum number of operating personnel per shift consistent with safe, efficient operation of the facility. 
The control philosophy as presently adopted was then applied to assign control functions to the central control room and to the local control stations. Control and monitoring functions, and where appropriate the particular equipment controls were then assigned to the central control room. 


\section{ACKNOWLEDGEMENT}

This work was supported by Ú. S. Energy Research and Development Administration Contract E(11-1)-3073 and Subcontract 192 thereto. Reproduction, translation, publication, use and disposal, in whole or in part, by or for the United States Government is permitted.

\section{LEGAL NOTIICE}

This report was prepared as an account of Government sponsored work. Neither the United States, nor the Administration, nor any person acting on behalf of the Administration:

A. Makes any warranty or representation, express or implied, with respect to the accuracy, completeness, or usefulness of the information contained in this report, or that the use of any information, apparatus, method or process disclosed in this report may not infringe privately owned rights; or

B. Assumes any liabilities with respect to the use of, or for damages resulting from the use of any information, apparatus, method, or process disclosed in this report.

\section{APPLIED TECHNOLOGY}

Any further distribution by any holder of this document, or of the data therein, to third parties representing foreign interests, foreign governments, foreign companies and foreign subsidiaries, or foreign divisions of United States companies, should be coordinated with the Director, Division of Thermonuclear Research, United States Energy Research and Development Administration. 


\section{TABLE OF CONTENTS}

Abstract

1. 0 Introduction

2. 0 Control and Monitoring Functions 3

3. 0 Number and Responsibility of Operators $\quad 7$

4. 0 Control and Monitoring Functions Assigned to the Central Control Room 12

5. 0 Operations Staffing, TFTR Complex 


\title{
1. 0 INTRODUCTION
}

This report documents a study performed to develop a central instrumentation and control philosophy for the TFTR facility. This study addresses the following questions:

- What are the various control and monitoring functions involved?

- How many and what different kinds of operating personnel are to be provided.

- How are the various control and monitoring functions, and as a result, the control personnel, to be assigned to the central control station?

- How is the crucially important experimental data handling, processing, and analysis function to be interfaced with the facility control functions?

\begin{abstract}
At the outset it must be recognized that the TFTR facility design is still at the conceptual stage; the facility arrangement has not been finalized and much of the major equipment has not been designed, e.g., the neutral beam systems. Hence, the central instrumentation and control philosophy and consequent equipment arrangement at this point in the development of the TFTR facility must be considered the first step in an iterative process from which the final control philosophy evolves. At this stage not only should the initial control philosophy be stated, but care should be given to documenting the basis to provide guidance and a departure point for later review and iterations.
\end{abstract}

Accordingly, this report has been prepared to formally state the control philosophy adopted and to discuss the principles underlying its choice. Each statement of the control philosophy addresses one of the specific questions above. 
The control philosophy is based on experimental nuclear reactor test operating experience, and conventional nuclear power plant and prototype power plant operating experience, modified as a result of discussions with cognizant engineers and managers for the various TFTR systems and with Princeton Plasma Physics Laboratory personnel who are most familiar with the anticipated operating modes of the TFTR.

The operational responsibility for the entire facility must reside clearly and unmistakably in one individual. That inidividual must be available in the Central Control Room whenever the facility is in a condition other than fully shutdown. When the individual currently in responsible charge of the facility leaves the control room for any reason, he must transfer the responsibility in an unambiguous fashion to a qualified person and record the fact in the facility log. The responsible individual may delegate responsibility to others. To avoid getting involved in the minutiae of a particular task to the detriment of the overall facility operation, the responsible individual should carry out all actual operations by directing others and should not personally operate switches, change'settings, etc.

The responsible individual must be provided with sufficient operational data to enable him to execute his responsibility. - Thus, for example, he must have status indications for all. major systems, and sufficient data to ascertain whether or not a.particular shot achieved the specified conditions. On the otherhand, he should not be burdened with data beyond that which is required for making an immediate operational decision. For example, if the facility loses incoming power, he does not need to be able to diagnose whether it is the result of an east coast blackout or something very, local. In any case of loss of off site power, the required action is.to secure the facility as though the outage would be of long duration, send out the available maintenance personnel to check the local equipment, and then execute recovery procedures when power is restored. 
The facility operators report to and work under the direction of a shift supervisor. The shift supervisor is normally the individual responsible for facility operations. The other person qualified to substitute for the shift supervisor would be the experimental operator.

The operating stations for the facility operators should reflect a philosophy similar to that used for the information supplied to the responsible individual for the facility. Each operator should have sufficient operational data available to permit him to make those decisions on which he is required to take reasonably prompt action. The operator should not be distracted with information which does not directly result in an action on his.part.

The guidelines provided above are part of the mechanism for determining which displays, data, and controls are provided in the Central Control Room main operating stations, and which are provided at local stations either within the Central Control Room or at other locations within the plant. To use these guidelines, it is necessary to actually define the operational sequences for both normal and abnormal conditions, and evaluate how often and how rapidly an action is required. Then it is possible to make rational decisions on the location of controls and displays.

The early stage of design of much of the equipment has not permitted this analysis to be carried out in detail and it would have been premature to attempt to do such an analysis in depth. A more general overview has been performed and some preliminary conclusions drawn. This information is presented in the following sections.

\subsection{CONTROL AND MONITORING FUNCTIONS}

The following is organized so that the statement of control philosophy is given in one paragraph, and the basis for this choice is given in the following paragraph. 


\section{A. Statement of Control Thilosophy}

1.: Control and monitoring of the TFTR facility will be provided under the following conditions:
- Post Installation Checkout
- Start-up
- Normal Experimental Operations
- Standby Conditions Between Experimental Operations
- Shutdown
- Maintenance and Testing of Facility Equipment and Systems Including Remote Maintenance
०: Selected Transient and Casualty Operations

2. .... To assign control functions and operating equipment location, it is assumed that the preferred method of operation is centralized control and monitoring for post installation checkout, start-up, normal experimental operations, standby conditions between experimental operations, shutdown and selected transient or casualty operations. Local control consoles, operating through the central control and monitoring system, is preferred for maintenance and testing operations.

3. Automatic control will be used to perform the central control,timing, and monitoring functions since the operator burden, operator time response, and equipment complexity and sophistication preclude the use of manual operation. It is also recognized that the automatic 
control, timing, monitoring and coordination required for the central instrumentation and control system necessitates a digital computer operated system.

\section{B. Basis for Control Philosophy}

1. Based on the current definition of the design, it appears that the TFTR facility will be operated such that start-up from "scratch" or complete shutdown of the facility will be relatively infrequent operations. For example, the vacuum system will have a relatively long start-up time ( 24 hours) if the starting point is a dry nitrogenfilled condition. Hence, to preclude the large amounts of wasted facility time, the vacuum system and other critical auxiliaries will be run to achieve a defined set of conditions (called "standby" herein) from which full experimental operation conditions can be achieved in a few hours. Therefore, the ability to maintain control of the facility in this standby condition must be provided. This requires staffing the TFTR facility for standby operations 7 days a week and 24 hours a day. Since the facility may be maintained in this standby condition for extended periods, the control system provided must also have the ability to simultaneously allow attendant equipment and system testing and maintenance operations.

The ability to perform all operations necessary to conduct the desired experiments must also be provided. For the purpose of this study, these operations are defined to include the transition from facility standby to full operational readiness to conduct experiments, the carrying out of experiments, and the transition back-down to facility stand-by. 
Finally, the TFTR facility must be designed to accommodate offnormal design conditions to prevent personnel hazard or significant equipment damage. The specific off-normal design conditions that are to be considered have not yet been defined.. These conditions must be defined before the TFTR control design can be finalized. They should include reasonably expected equipment failures and personnel errors.

2 Installation and startup operations for the numerous TFTR systems and components will require energizing, tuning, and alignment of a large amount of equipment. This equipment normally requires little operator attention once it is operating. On this basis, normal practice will utilize the central control and monitoring system (CCMS) to remotely operate this equipment. Control modes and system operating parameters will be selected by the operator(s) at the control consoles in the central control room by means of keyboard entries and console switches. Once full operational status is achieved, the equipment is monitored much less frequently. The control and critical monitoring functions are performed automatically by the CCMS, providing panel readout alarms for operator attention, and providing readout displays of operating parameters as selected by the operator(s). Shutdown operations are performed by the CCMS with appropriate operator inputs similar to that used for startup. In addition, the ability to test equipment and perform maintenance must be provided by local stations while operating through the CCMS.

This will provide normal control and extended monitoring capabilities for testing hardware. This general operating philosophy has been adopted for the TFTR. 
Bit is assumed that normal procedure will be to operate from the "stand-by condition in which control of the TFTR facility can be concentrated in one centralized location and a small number of operators be provided to operate the controls to bring the facility up to a condition where experiments can be performed, carry out the experiments, and return the facility to stand-by. This operating philosophy requires that sufficient control and monitoring equipment be provided in the centralized control station to allow the necessary experimental functions to be carried out.

It is important to note that the use of a relatively small number of operators requires special provisions to control and mitigate the consequence of equipment failures, malfunctions, or off-normal conditions. The potential for operator error and loss of off-site power must also be anticipated. Consequently, the facility must be controllable and safe when the fewest number of operators are on station in the plant. This requires that the centralized control station be provided with the means to detect and respond to these anticipated transients.

3. To fully evaluate and understand what happens during each pulse operation of TFTR, it will be necessary to monitor and record many thousands of words of data for each pulse. Furthermore, to assure flexible, reliable, and repeatable performance a high performance automatic control system is required. Considering the control, timing, and monitoring requirements, as defined in the Central Instrumentation and Control System Description (SD-4G), a digital computer system is a necessity.

\section{0 NUMBER AND RESPONSIBILITY OF THE OPERATORS}

The following is organized so that the statement of control philosophy is given in one para- 
graph, and the basis for this choice is given in the following paragraph.

A. Statement of Control Thilosophy .

The number of operating personnel per shift will be the minimum consistent with safe, efficient operation of the facility. This minimum level must be determined by analyzing the burden on the operators during operation of the facility during normal conditions and under off-normal transient or casualty operations. Based on the facility design definition to date, it appears that a control group consisting of a test director, a shift supervisor, an experimental device operator, four operators and four to six experimenters/ physicists will meet this objective. The following tentative responsibility assignments hạve been made:

\section{Test Director}

This individual is qualified and responsible for conducting the basic experimental program during the shift and is also in overall charge of the facility. He is responsible for assuring that the facility is operated so that personnel are not endangered, no equipment damage occurs, and the experimental data obtained is valid. He shall be the final authority for directing the Shift Supervisor as to the test set-up for any particular experiment. The Test Director has no fixed station assignment; he can move through the facility as required. His normal location is expected to be in the central control room, and a desk with interactive computer terminal shall be provided adjacent to the central control room for the Test Director. The Test Director is also the final authority normally available in the facility to conduct day-to-day experiment operations. As a băsis for perperiments to be carried out. As a basis for performing a particular experiment the Test Director will hove to receive and understand information from three sources: 
(a) Facility operating status information primarily available through facility operator personnel.

(b) Physics experimental data, e.g., plasma diagnostic information, available from the physicist-experimenters.

(c) Overall test program information available from formal facility test plan documentation or perhaps from a steering committee which provides overall guidance in the selection and sequencing of specific experiments.

2. Shift Supervisor

Staff Engineer on the shift. Qualified and responsible for overall facility operations and directs all other operators in performance of their tasks. Coordinates facility operation to meet needs of the basic experimental program and to meet specific test needs given by the Test Director. The Shift Supervisor is always located in the central control room, except during special times when he may be substituted by the experimental device operator. The Shift Supervisor is the primary advisor of the Test Director as far as facility operational capability or status is concerned. Facility is operated per operating manual. A staff of four shift supervisors is needed for the 7 days a week and 24 hours a day operations.

3. Experimental Device Operator

Qualified and responsible for selecting control mode and system operating parameters by means of keyboard entries and console switches for central control and monitoring of all TFTR systems. In addition, he will have a working knowledge of the central control and mónitoring system and all operation functions in the central control room. The Experimental Device Operator station is located in the central control room. A staff of four experimental device operators is needed for the 7 days a week and 24 hours a day operations. 
4. Control Room Operators

In addition to the above, four qualified control room operators will be utilized on daylight shift for operations, control, and monitoring of all TFTR systems from the central control station. Of particular concern are the electrical power, neutral beam, and data handling systems and the major experimental device auxiliaries, e.g., the vacuum pumping system, the fuel gas systems and the cooling water systems. The Control Room Operators are normally located at the central control station albeit a maximum of two operators may leave for short periods of time to operate facility equipment, etc. In their absence, the Shift Supervisor or the Experimental Device Operator will perform any functions needed in the control room. In addition, one qualified control room operator is needed for each of the second and third shifts and for weekends.

\section{Physicist-Experimenters}

These individuals are physicists who participate in performing experiments in the facility. In general, their function is limited to reviewing the experimental data resulting from a given experiment and advising the Test Director as to the specific parameter settings to be used in a given experiment. One of the Physicist-Experimenters will be in overall charge of the others to provide a coordinated output to the Test Director. Under specified conditions, one or more physicist-experimenters may be operating or adjusting instrumentation or other auxiliary equipment attached to the basic experimental device. Six stations with interactive computer consoles will be provided in or adjacent to the control room to accommodate Physicist-Experimenters. These consoles will be data handling and processing or data manipulation stations only. No control functions will be initiated from these consoles. 
B. Basis for Control Philosophy

The number of operators is based on the assumed responsibilities assigned to each operator as defined in the preceding section. On this basis, the assigned responsibilities are the basis for selecting the number of personnel. It must be recognized this is a first iteration, and as the facility design becomes further detailed, the actual burden associated with these responsibilities may justify increasing or reducing the number of operators. In any case, these categories of personnel should be provided.

1. Test Director

In this person resides the central, overall responsibility for the facility. He should be free from actual control operation assignments so that he can provide full, thought ful attention to the overall operation of the facility and the experiment so that he can meet his responsibility.

2. Control Room Operators

These are trained personnel familiar with the facility equipment who actually operate the equipment. One of these must be designated as the Shift Supervisor to assure organization and control of all operating activities. The Shift Supervisor reports to the Test Director.

3. Thysicist/Experimenter

These are physicists who provide assistance to the Test Director in planning a given experiment and analyzing the results of a given experiment. They have no operational control of the facility or its equipment. One of these must be designated as the lead experimenter to assure organization and coordination of thcir activities. 


\section{0 CONTROL AND MONITORING FUNCTIONS ASSIGNED \\ TO THE CENTRAL CONTROL ROOM}

The current conceptual design of the TFTR systems and the present plans for operating the pulsed experiments were reviewed in order to determine the control functions and control monitoring that would be needed to take facility equipment through the anticipated. operations.

The operations considered were:

- Post Installation Checkout

- Start-up to the stand-by condition

o. Normal experimental operations

-: Stand-by conditions between experimental operations

- Shutdown

- Maintenance and testing of facility equipment and systems including remote maintenance

- Selected transient and casualty operations

The control philosophy discussed in the previous section was applied to assign control functions to the central control room and to the local control stations. "The following paragraphs list the control functions, parameter monitoring, and where appropriate the particular equipment controls that were assigned to the central control station.

A. Central Control and Monitoring System (CCMS)

The function of this system is to program the experimental operating mode and to initiate operation of all systems that contribute to the execution of an individual pulse experiment. In addition, for each experiment the CCMS must verify the operational readiness of the following systems prior to initiation of magnetic field current build up: 
- Toroidal, ohmic, and equilibrium field current electrical power supply systems

- Neutral beam injection systems

- Fuel gas handling systems

- Torus vacuum pumping system

- Machine area water cooling system

The experimental device operator described in the previous section is responsible for monitoring and controlling the operation of the CCMS. He will be required to program the magnetic field current-time pulses, verify the stand-by status of all systems, and to initiate the automatic timing system which controls the various systems during the experiment pulse. In addition, he is responsible for verifying that the various systems performed within tolerance during the previous experiment. Consequently, control equipment is to be provided in the central control room to enable the experimental device operator to perform the above functions.

1. Toroidal, Ohmic, and Equilibrium Field and Neutral Beam Pulsed Power Conversion Systems

Operation of these systems during the experiment is initiated and controlled by the CCMS. Consequently, sufficient status and parameter information and control functions must be provided in the central control room by which to provide the necessary control and moni-. toring capabilities. Listed below are the capabilities that must be assigned to the central control room required to accomplish this objective. The four power conversion systems are considered together because essentially identical control functions are required for each. The capability must exist to:

- Provide command signals to the field coil and neutral beam power conversion systems for stand-by operations.

- Perform emergency disable and/or shutdown of the power conversion systems. 
- Provide command signals to the field coil and neutral beami power to start a normal shutdown

- Provide demand signals that establish current-time characteristic to be generated by the power conversion systems.

- Provide command signals to initiate magnetic field currents and neutral beams during pulse operations.

- Monitor the stand-by status of the power conversion systems.

- Receive analog electrical measurement signals from each of the magnetic field coil and neutral beam power conversion systems.

- Receive a signal indicating a fault in a power conversion system.

\section{Non-Tritium Charge Gas Delivery System}

The non-tritium charge gas delivery system stores the on-site high purity stable isotope gases $(H-1, H-2, H e-3$ and natural $H e)$ to be used in the plasma physics experiments, further purifies these gases by selective permeating processes, and on demand delivers prescribed quantities of these gases to the torus during each experiment. The non-tritium gas handling system is brought to the stand-by condition by operation of the CCMS from the central control room. Hence, all process parameters must be monitored and displayed or otherwise made available to the central control room operator. In addition, during normal experiment operations, all process controls will originate in the central control room. In particular the following monitoring and control functions must be performed in the central control station:

- Monitoring temperatures of:

- Hydrogen diffuser heaters

- Helium permeater heaters.

- Measuring volume chambers

- Cooling water supply and return lines 
- Monitoring pressures of:

- Inlet and discharge sides of the diffusers and permeaters

- Measuring volume chambers

- Discharge side of supply tank-regulating valves

- Providing measuring volume cooling water flow indication

- Controlling the heating rates and operating temperatures of the hydrogen diffusers, helium permeaters, measuring volumes, and cooling water flow rate to the measuring volumes.

- Controlling the pressures of the fuel gases at the delivery side of the storage tank pressure reducing-regulating valve, entrance and exitside of the diffusers and permeaters, and within the measuring volumes.

- Shutting down the non-tritium fuel gas handling system.

- Performing emergency shutdown of a diffuser or permeater heater upon receipt of a heater high temperature signal.

\section{Tritium System}

The tritium system stores the on-site inventory of tritium to be used in the plasma physies experiments, maintains the purity of the stored tritium, further purifies the tritium via a diffusion process, and on demand delivers prescribed quantities of tritium to the torus for each of the TFTR pulsed two component operations. The CCMS maintains sole control over tritium handling including startup and shutdown and ensures that a loss of facility power will not result in an accidental release of tritium. Hence, all tritium process parameters and controls must be monitored and displayed in the central control room. The functions assigned to the central control room are:

- Monitoring temperatures of:

- Tritium generator heater

= Palladium diffuser heater 
- Measuring volume chamber

- Cooling water supply and return

- Monitoring pressures of:

- Containment atmosphere

- Discharge from the palladium diffuser

- Measuring volume chamber

- Inert gas supply (high and low side)

- Monitoring operative indication of the closed cycle water cooling package and gas circulation of atmosphere cleanup system.

- Bringing and maintaining the tritium storage and delivery system to the stand-by status.

- Controlling the heating rates and operating temperatures of the:

- Tritium generator

- Palladium diffuser

- Measuring volume

- Supply water of the closed-cycle cooling water package

- Controlling pressures of:

- Containment atmosphere

- Measuring volume

- Gas discharge from the palladium diffuser

- Delivery side of the argon atmosphere supply

- Performing emergency shutdown of the tritium generator or palladium diffuser heater upon receipt of a heater high temperature signal. 
- Controlling opening and closing sequencing for all operations of the tritium storage and delivery system valves. Specifically:

- $\quad$ Tieing into the torus vacuum pumping system

- $\quad$ Charging the measuring volume

- Flowing the tritium into the supply conduit

- Equilibrating the pressure in the conduit and measuring volume

- Injecting the tritium into the torus

- Isolating the tritium into the torus

- Isolating various portions of the tritium system gas manifolding

- Operating the containment interconnection valves

- Controlling the closed-cycle water cooling package

- Controlling the inert gas atmosphere pressure control

\section{Tritium Cleanup System}

The tritium cleanup system detritiates the atmospheres of facility areas where tritium is handled or released. It consists of five separate installations. Two of these installations are intended to perform emergency recovery operations in the event of an accidental tritium release in the test cell, shielded box, warm cell, or hot cell. The other three, which are relatively small, operate routinely on the atmospheres of the tritium system containment, fuel vault, and torus and spent plasma gas residues. The CCMS maintains sole control over all processing concerning tritium handling and is responsible for ensuring that a loss of facility power will not result in accidental release of tritium. 'Hence, all tritium process parameters and process' controls must be monitored and displayed in the central control room. These include: 
- Monitoring temperatures of:

- Regenerative heat exchanger gas discharge

- Preheater gas discharge

- Catalytic oxidizer gas discharge

- After-cooler water discharge

- After-cooler gas discharge

- Monitoring pressures of:

- Gas circulator gas discharge

- Catalytic oxidizer gas discharge

- Gas supply to the desiccator

- Providing gas sampling capability at the discharge side of the desiccator beds for the purpose of monitoring the tritium level of the cleaned gases.

- Placing the cleanup systems in operating condition and shutting them down.

- Controlling the heating rates and gas temperatures of the gases fed to the catalytic oxidizer.

o: Controlling the cooling water flow to the after-coolers.

- Performing emergency shutdown of the gas preheater upon receipt of a heater high temperature signal.

- Controlling the valve sequencing of all units except for the tritium generator enclosure to accomplish:

- Placing units into service and shutting them down

- Interfacing the units with items to be serviced, e.g., torus, nongetterable gas holdup tanks, hot cell

- Interfacing with the ventilation ducts and exhaust ducts of areas to be serviced 
- Dispatching samples of area and treated gases to the tritium monitors

- Charging the torus with air in preparation for a torus cleanup

- Regulating the flow of "moisture swamp" *

- Monitoring cleanup progress

5. Torus Vacuum Pumping System

The torus vacuum pumping system consists basically of mercury diffusion pumps backed by mechanical pumps exhausting into a closed system in order to preclude discharge of tritium to the test cell or the environment. The torus vacuum equipment is installed and maintained by means of local control while tied to the remote CCMS. The torus vacuum system control operations and monitoring responsibility is provided by the CCMS. Hence, all process parameter monitoring and system control needed for normal experimental operation and to cope with transients and casualties must be provided in the central control room. Hence, the following monitoring and control functions as a minimum must be performed in the central control stations:

Monitoring and controlling foreline and exhaust line temperatures and pressures

- Controlling zeolite trap heaters

- Monitoring of torus pressure and partial pressures

- : Tritium level monitoring of foreline

$\therefore$ Monitoring of equipment temperatures

- Controlling selected valves located within hazardous areas

- Automatic closing of the ultra-high vacuum (UHV) isol ation valves in the event of a failure such as a torus vessel leak or a power failure.

6. Machlne Area Water Cooling System

The machine area water cooling system removes heat generated in the toroidal, ohmic

* Moisture swamping connotes adding water vapor to gas stream being treated to enhance the dessication of the tritiated water. This corresponds to the common radiochemistry carrier technique utilized in decontamination technology. 
heating, and equilibrium magnetic field current coils and in the solid state rectfiers of the energy conversion systems and discharges to the general purpose facility water cooling system. In addition, the system is responsible for maintaining proper cooling water chemistry. Current plans are to perform control of the machine area water cooling system automatically via a process computer. The computer would control cooling water temperature, flow rate, and pressure level to be compatible with the design of the electric components. This automatic control system is therefore responsible for monitoring and controlling the operation of all motor-compressor chiller units, circulating pumps, and valves in addition to monitoring all process temperature, pressure, and flow parameters. In addition, it must be capable of identifying equipment failures, e. g., high temperature, low flow, and of isolation of affected portions of the system. The machine area water cooling system process control computer input and parameter monitoring will be performed in the central control room.

\section{Facility Cooling Water System}

The facility cooling water system removes heat from the motor generators, capacitor bank resistors, neutral beam water chiller, machine area water cooling.system, test cell air conditioner, hot cell air conditioner, and the computer and office air conditioning equipment. In addition, the system is responsible for maintaining proper water chemistry. The facility cooling water system heat sink is an evaporative cooling tower. Control of the heat exhaust is via variable speed fans. This system has not been defined in detail at this point, however, one can anticipate that the following monitoring and control functions will be required as a minimum:

- Startup, shutdown, and monitoring of the cooling water pumps and motors cooling tower

- Control of cooling tower fan speed

- Control and position monitoring of all flow control valves 
- Control and monitoring of water chemistry.

- Perform emergency shutdown of all equipment requiring cooling water upon failure of cooling water system

- Monitoring for abnormal temperatures and low flow in all critical paths

- Leak detection

The facility cooling water system controls and monitoring will be performed in the central control room.

\section{Liquid Nitrogen and Gas Storage System}

The liquid nitrogen and gas storage system provides the cryogenic coolant for the neutral beam pumping system, the cold nitrogen for other gas cooling requirements, and the gas storage for the inert gases used for valve operators, inert gas flushers, and inert ambients such as the tritium generator enclosure and the tritium measuring device enclosure. The liquid nitrogen system will consist of a liquid nitrogen recirculator and a 10, 000 gallon liquid nitrogen dewar. However, the system has not been developed in any. detail at this point. The inert gases will be stored in a group of high pressure cylinders arranged in rechargeable nested arrays serviced via mobile truck suppliers. Again, no detailed requirements of this system have been defined. Much of the control of the nitro- . gen cooling system will be the responsibility of the neutral beam control operators, and it is not apparent at this point whether the containments with inert atmospheres will be handled on a batch or continuous flow basis. It is presently assumed that all control functions and monitoring required to maintain these systems in the stand-by condition will be provided in the central control room. 


\section{Safety and Protection System}

The safety and protection system (SPS) is hard-wired and designed to minimize situations which are hazardous to personnel or equipment, to monitor the conditions which exists, and in the case of undesired conditions cause the equipment to revert to a safe condition and sound an alarm. In addifion, the SPS will provide interlocks for all electrical systems and for access to all electrical systems that can create hazardous conditions. Part of this system will be composed of "key exchange interlocks." The control functions of the safety and protection system will be distributed throughout the various systems' equipment under control of the operator in the central control room. In addition, the status of all facility personnel safety, monitors and interlocks will be annunciated in the central control room.

B. Radiation and Tritium Monitoring System

The radiation and tritium monitoring system provides neutron, gamma, tritium and effluent monitoring functions as required for operation of the overall TFTR facility. Specific functions include:

- Monitor gamma radiation levels in all hot cell areas requiring personnel access

- Monitor tritium levels in all areas in which tritium is handled

- Tritium monitoring devices shall be of the continuous reading type, with recording and visual/audible alarm features to indicate setpoint exceeded

- Trịium monitors shall be situated as a minimum at:

- Test cell

- Tritium cleanup equipment area

- Facility exhaust duct

- Transfer bay

- Hot cell 
- Fuel vault

- Tritium storage and generation areas

- Exhaust lines of desiccant unit of cleanup systems

- Inlet of torus tritium cleanup system

- Exhaust from vacuum system mechanical pump

- Diagnostic equipment area

- Test cell ventilation equipment area

- Tritium monitors will have an adjustable setpoint. When the setpoint is exceeded, the alarm will signal ventilation system to go into the recirculation mode and will indicate the condition in the central control room. Manual reset will be in the central control room.

- Neutron, beta and gamma radiation will be monitored and recorded on a continuous basis. Alarms are indicated in the central control room and reset in the central control room. Detectors shall be situated as a minimum at:

$-\quad$ Test cell

- Exterior wall of test cell

- Warm cell

- Gallery areas

- Test cell chiller room

- Diagnostic equipment area

- Mockup assembly area

- Neutral beam test cell 
The radiation level readouts, data logging and alarms for the above monitors will be provided in the central control room.

\section{Plasma Diagnostics}

As currently envisioned, there is to be a minimum of four experimenter physicists in the experimenter/physicist room located immediately adjacent to the central control room. Space is provided for six interactive computer consoles to allow the physicists to analyze experimental data and make recommendations concerning experimental parameters to the test director. They have no duties concerning operational control of the facilities. The space allocations for the physicist experimenters are included in the central control room area.

\section{0. OPERATIONS STAFFING, TFTR COMPLEX}

Operations staffing (engineers, technicians, operators, etc.) for the TFTR complex is based on a normal work week of one shift per day coverage except in the Control Room where, in addition to the normal operating crew, reduced staffing is provided for back-shifts and week-end support. The reduced staffing is necessary to assure safe, positive control of the overall test complex during operational stand-by, back-shift maintenance operations, pretest preparations, equipment checkout and special tests. Table 5- l, Operations Staffing; TFTR Complex, summarizes the manning levels considered necessary to operate and maintain the facility in a continuous ready to operate condition.

\section{A. Control Room}

Operations staffing consists of a Director, Test Facility; four Shift Supervisory Engineers; four Experimental Device Operators; seven Operators and two maintenance technicians. A normal crew will consist of a shift supervisory engineer, one experimental device operator, four operators and two 
maintenance technicians. The back-shifts and week-end operating crews will consist of a shift supervisory engineer, one experimental device operafor and one operator. All operating crews will be trained to a predetermined qualification and acceptance criteria. Only trained personnel, determined to be qualified and accepted, will be permitted to operate the control room/ test facility.

In addition to the operating crews, a Chief Test Engineer will be trained and considered part of the Control Room Staff. The Chief Test Engineer will supervise the Test Engineers responsible for the various technical support through-out the overall test facility. The Chief Test Engineer will report to the Director, Test Facility.

\section{B. Experimental Area/Neutral Beam Power Supply Area}

The maintenance staff will consists of one Experimental Test Engineer and four technicians. The crew will be trained in all phases of preventive maintenance, resolution of malfunctions, operation of equipment, safety of operations and Rad Con consideration as related to the Test Cells and Neutral Beam Power Supply area. The Experimental Test Engineer will report to the Chief Test Engineer.

C. Motor Generator and Puwer Conversion

The maintenance and functional operating crew will consist of one Test Engineer and three technicians. The crew will be responsible for all maintenance operations as well as functional control of the Motor Generator/ Power Conversion system during testing. Operational Control will be from the central Control Room. The crew will be trained in its responsibilities and will function as a team with the Test Engineer reporting to the Chief Engineer. 
D. Rad Con - Health Physics

The Rad Con-Health Physics repsonsibilities, associated with operating the Experimental Area, will be satisfied with a crew consisting of one Rad ConHealth Physics Engineer, one Rad Con Foreman and three Rad Con Technicians. This crew will be trained to support maintenance and test operations in the Experimental Area as well as their normal Rad Con responsibilities. The Rad Con-Health Physics Engineer will receive directions and request for support from the Director, Test Facility.

E. Engineering Support/Maintenance

A general purpose engineering, technician and operator staff is required to support the overall effort of the special crews discussed in $A, B, C \& D$. This crew will consist of three Test Engineers, two Foreman, sixteen technicians and five manipulator operators. A Servicing Engineering, trained in servicing and remote handling operations will also be part of the Engineering Support Crew. The general crew will be trained to support the maintenance operations associated with the test facility. The Test Engineers will report to the Chief Test Engineer; the Foremen, responsible for all technicians in the general crew as well as special crews, will report to the Director, Test Facility and the Servicing Engineer will also report to the Director, Test Facility. 
TABLE 5-1

\section{OPERATIONS STAFFING TFTR COMPLEX}

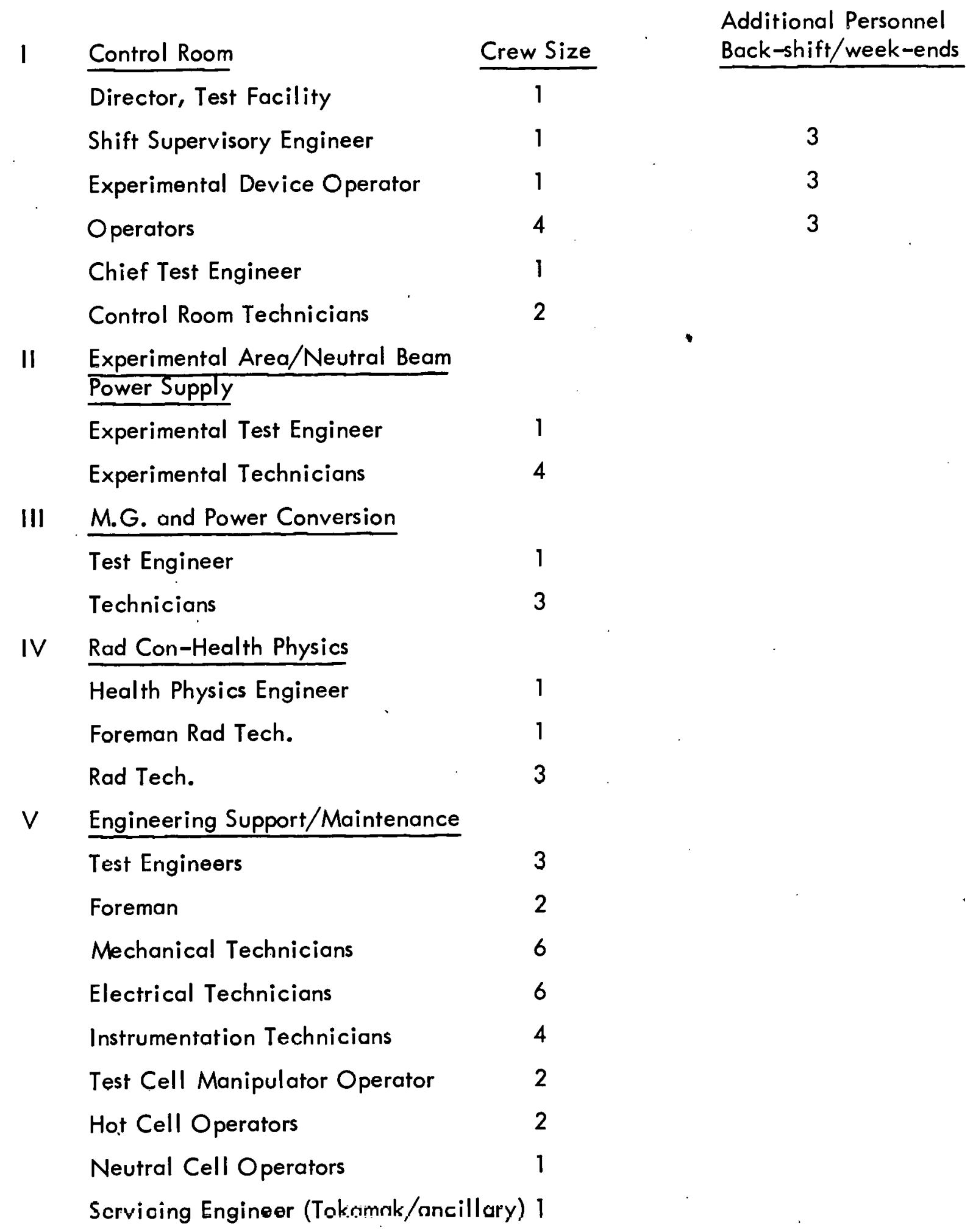

